\title{
Current practice about the evaluation of antibody to streptolysin O (ASO) levels by physicians working in Antananarivo, Madagascar
}

\author{
Zafindraibe Norosoa Julie ${ }^{1}$, Randriamanantany Zely Arivelo $^{2}$, Rajaonatahina Davidra Hendriso ${ }^{1}$, Andriamahenina \\ Ramamonjisoa ${ }^{1}$, Rasamindrakotroka Andry ${ }^{1}$
}

1. University center hospital of Antananarivo, Para clinic unit of immunology, Antananarivo, Madagascar

2. University center Hospital of Fianarantsoa, Laboratory unit, fianarantsoa, Madagascar

\begin{abstract}
Introduction: The diagnosis of post streptococcal diseases is usually confirmed by immunological tests. Only the antistreptolysin $\mathrm{O}$ is usually prescribed by physician. This study aimed to describe the current practice of these requests in Antananarivo.

Methods: It was a retrospective and descriptive study conducted at the Para clinic Unit of Immunology at the University Center Hospital of Antananarivo. We analyzed all requests during seven years, from January 2003 to December 2009. We looked at age, gender, and clinical symptoms which led to the request and the result for each request.

Results: We retained 4143 requests for antistreptolysin $\mathrm{O}$ titration in our study. The mean age of the study participants was 32.9 years with $18.3 \%$ of participants being less than 15 years old. The main symptoms leading to the request of this analysis were rheumatologic (41\%), followed by neurological (13.9\%) and cardiologic symptoms $(8.5 \%)$ and $19.4 \%$ were prescribed for various symptoms. Only 15\% of all requests had a value more than $200 \mathrm{U} / \mathrm{ml}$.

Conclusion: Our study found that in most of requests, ASO titre levels were not significant.
\end{abstract}

Keywords: ASO titration - Antananarivo - Post streptococcal infections

African Health Sciences 2014; 14(2):384-389

DOI: http://dx.doi.org/10.4314/ahs.v14i2.14

\section{Introduction}

Post streptococcal disease caused by beta hemolytic streptococcus group A comprise joint involvement, acute renal failure, abnormal involuntary movements, and cardiac involvement ${ }^{1,2}$. Joint pain can be divided into two distinct presentations: acute rheumatic fever whose peak age is $5-15$ years ${ }^{3,4}$ and which can be a potential source of complications such as heart diseases ${ }^{5}$; and post streptococcal arthritis ${ }^{6,7}$.

The prevalence of post streptococcal diseases considerably decreased in industrialized countries but it still remains a major public health concern among developing countries ${ }^{8,9}$. Immunological testing is necessary in order to prove that clinical symptoms are caused by post streptococcal diseases: by performing

\section{Corresponding author:}

Randriamanantany Zely Arivelo

Mailing address: Lot III C 1

bis ambanin'ampamarinana

Email: zrandriamanantany@yahoo.fr

Fax: none

Phone number: +261 343677308 two antibodies tests such as antistreptolysin O (ASO) and antistreptodornase $\mathrm{B}$ which are directed against extracellular antigen of streptococcus of group $\mathrm{A}^{10}$.

Only the titration of ASO is currently available in labs within any public health centers in Madagascar. This study aimed to describe the current practice of these requests in Antananarivo.

\section{Methods}

We conducted a retrospective and descriptive study during a period of seven years from January 2003 to December 2009, at the Para clinic unit of Immunology at the University Center Hospital Joseph Ravoahangy Andrianavalona, Antananarivo, Madagascar.

All requests from both inpatients and outpatients of ASO were included in this study, and we excluded incomplete data, especially those in which the age was missing. The variables which were recorded for each individual request were the age of the patient, the gender, the clinical symptom mentioned by the physician for the request of ASO titration and the ASO titre value of each request. As there was no epidemiological study done in order to determine the normal valoe of ASO titer in Madagascar, we retained as significant all ASO 
titre values more than $200 \mathrm{U} / \mathrm{ml}^{6}$. Three milliliters of blood was obtained by venipuncture of the forearm, and then it was centrifuged with $1500 \mathrm{~g}$ during 10 minutes. As the test was made once a week, the serum was stored at $+4^{\circ} \mathrm{C}$ until the test was made. The titration of ASO level was performed with a latex agglutination technique (Humatex ASLO ${ }^{\circledR}$ (Human $\mathrm{GmBh}$ )) according to the manufacturer instructions. 50 microliters of serum was mixed with one drop of the latex reagent, and then it was shaken with a Kline shaker with $100 \mathrm{rpm}$ during 2 minutes before reading it.

We used Epi info software version3.5.1 (CDC Atlanta) for the statistical analysis.

\section{Results}

There were 4149 requests of ASO titration during the whole period of study and we retained 4143 of them.

Table I: Frequency of symptoms leading to a request of ASO

\begin{tabular}{|c|c|c|c|}
\hline Type of symptoms & Clinical information & Frequency & $\%$ \\
\hline \multirow{3}{*}{$\begin{array}{l}\text { Rheumatologic } \\
(41,00 \%)\end{array}$} & Arthralgia & 1475 & $35.60 \%$ \\
\hline & Arthritis & 131 & $3.16 \%$ \\
\hline & Others $^{(1)}$ & 84 & $2.03 \%$ \\
\hline \multirow{3}{*}{$\begin{array}{l}\text { Neurologic } \\
(13,90 \%)\end{array}$} & Chorea & 28 & $0.68 \%$ \\
\hline & Seizure & 103 & $2.49 \%$ \\
\hline & Others ${ }^{(2)}$ & 440 & $10.62 \%$ \\
\hline \multirow{4}{*}{$\begin{array}{l}\text { Heart diseases } \\
(8,50 \%)\end{array}$} & Cardiomyopathy(3) & 53 & $1.28 \%$ \\
\hline & Valvulopathy(4) & 165 & $3.98 \%$ \\
\hline & Endocarditis & 43 & $1.04 \%$ \\
\hline & Others $^{(J)}$ & 91 & $2.20 \%$ \\
\hline \multirow{3}{*}{$\begin{array}{l}\text { Nephrology } \\
(3,20 \%)\end{array}$} & Acute renal failure & 7 & $0.17 \%$ \\
\hline & Glomerulonephritis & 5 & $0.12 \%$ \\
\hline & Others $^{(0)}$ & 30 & $0.72 \%$ \\
\hline \multirow{2}{*}{$\begin{array}{l}\text { Oto Rhino Laryngology } \\
(2,40 \%)\end{array}$} & Tonsillitis & 94 & $2.27 \%$ \\
\hline & Others( $^{(1)}$ & 5 & $0.12 \%$ \\
\hline \multirow{3}{*}{$\begin{array}{l}\text { Dermatology } \\
(1,30 \%)\end{array}$} & Nodula & 4 & $0.10 \%$ \\
\hline & Erythema & 16 & $0.39 \%$ \\
\hline & Others $^{(8)}$ & 35 & $0.84 \%$ \\
\hline $\begin{array}{l}\text { Edema }^{(श)} \\
(2.15 \%)\end{array}$ & & 89 & $2.15 \%$ \\
\hline $\begin{array}{l}\text { Others }^{(10)} \\
(19,72 \%)\end{array}$ & & 817 & $19.72 \%$ \\
\hline $\begin{array}{l}\text { No clinical information } \\
(10,33 \%)\end{array}$ & & 428 & $10.33 \%$ \\
\hline TOTAL & & 4143 & $100.00 \%$ \\
\hline
\end{tabular}

(1) : Bone pain, backpain, functional disability

(2) : Headache, stroke, hemiplegia,

(3) : ischemic, hypertrophic, dilated or restrictive cardiomyopathy

(4) : all heart valves sounds abnormalities confirmed or not by echography

(5) arterial hypertension, pericarditis, heart angina,

(6) : dysuria, urinary infection

(7) : keratitis, otitis, keratoconjonctivitis

(8) : cutaneous eruption, furunculus, eczema

(9) : all causes of edema

(10) : vertigo, tuberculosis, chickenpox, behavioral disorder, stiff neck 
The mean age was 32.9 years (ranging from 01 to 89 years), with a female predominance $(62.3 \%)$. Only $18.3 \%$ of all requests came from children under 15 years of age (fig 1 ).

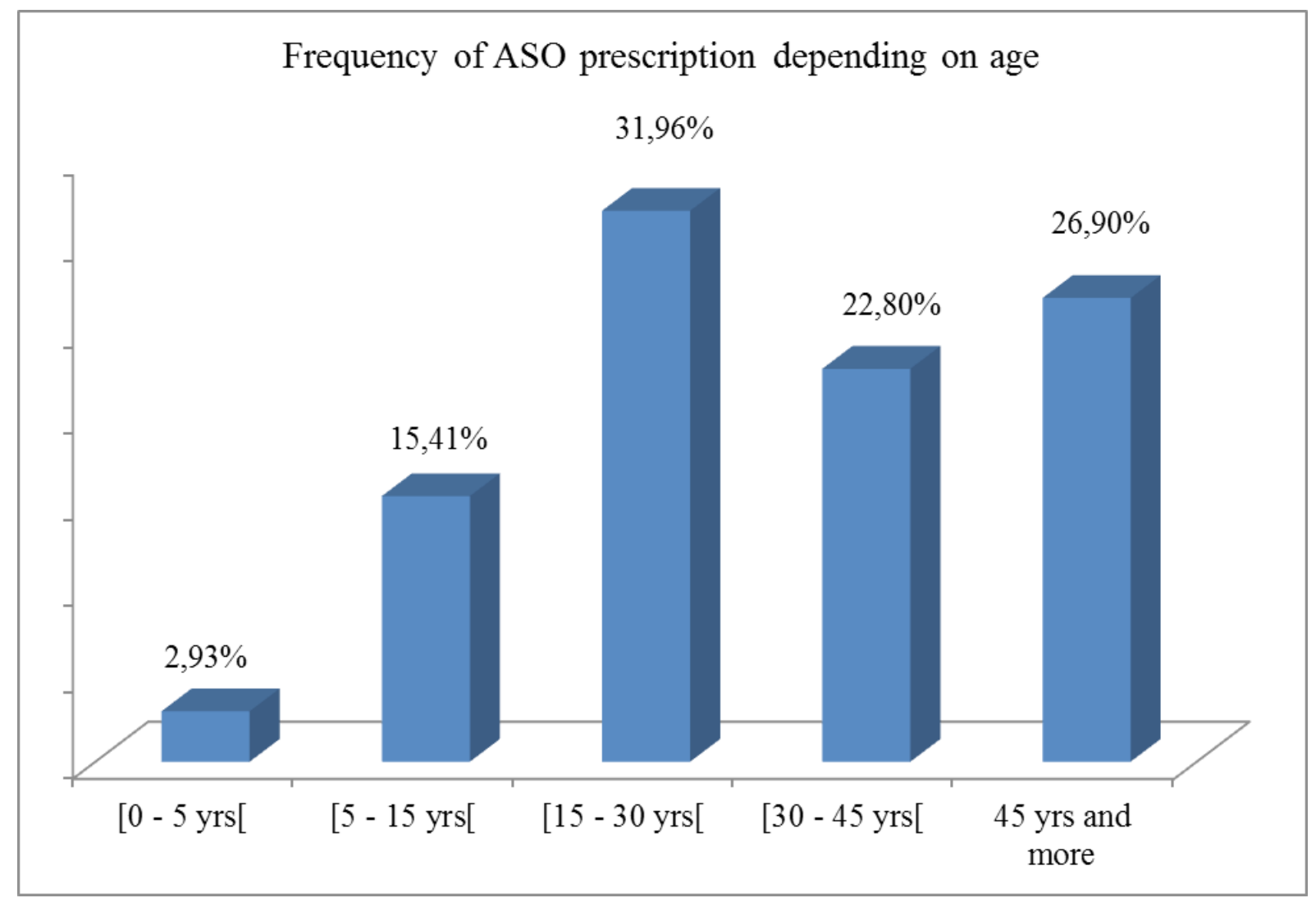

Figure 1: Frequency of ASO prescription depending on age

Rheumatologic, neurologic and heart diseases were the most frequent causes of request. For the rheumatologic symptoms, arthralgia $(35.6 \%)$ and arthritis $(3.2 \%)$ were the most frequent. For the neurological symptoms, chorea $(4.91 \%)$ was the most frequent and for heart diseases, valvulopathy $(46.87 \%)$ was the most frequent. Almost $10.3 \%$ of all requests $(4,143)$ did not contain any clinical information. For $19.72 \%$ of requests $(4,143)$, the main symptom which led to an ASO titration did not correlate with any disease related to streptococcal infection, such as Burkitt lymphoma, dizziness, Grave's disease, delirium tremens, acute leukemia, limp etc.

The figure 2 shows the ASO tire levels of all requests. Only $15 \%$ of the request had significant ASO titres, with those with "borderline normal" (ASO titre $=200$ $\mathrm{U} / \mathrm{ml}$ ) being $23 \%$. 


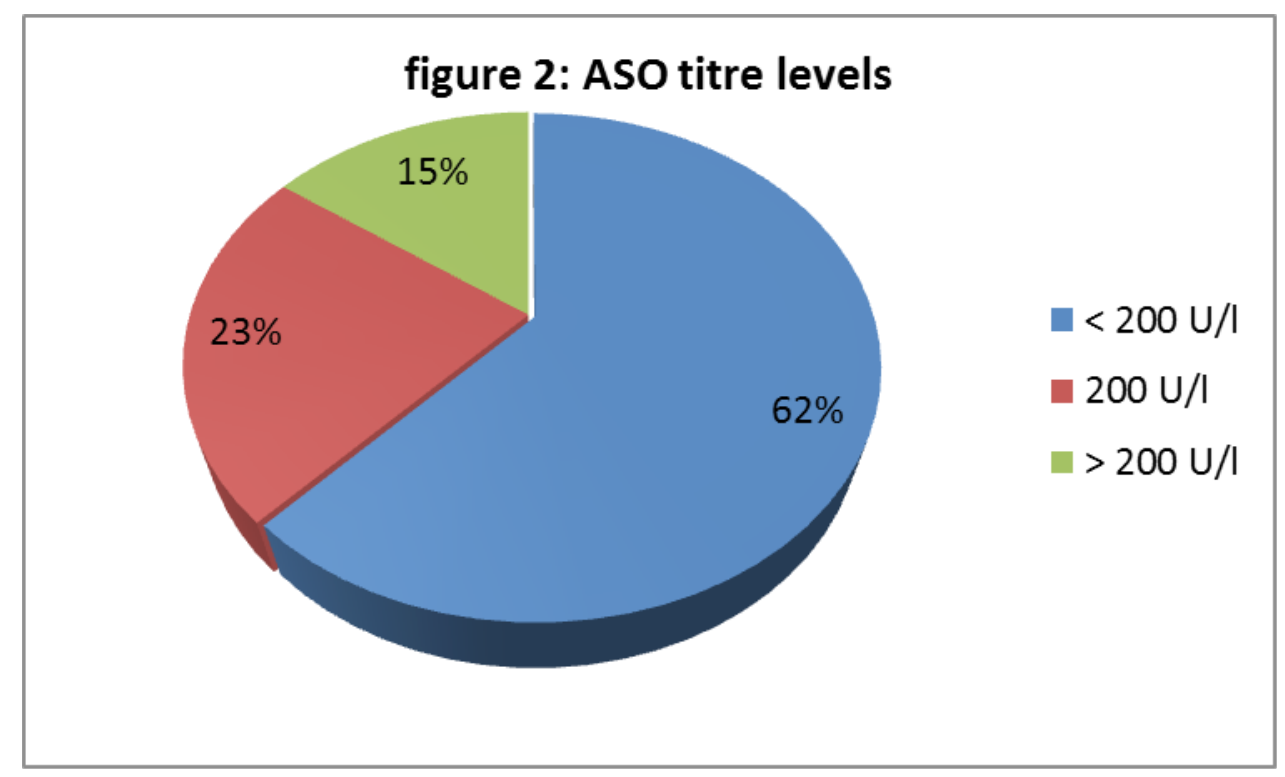

Figure 2: ASO titre levels

The figure 3 shows the distribution of ASO titre levels depending on the type of symptoms. No abnormal ASO titre value was found for gynecological symptoms and tor the others, these abnormal values ranged from
$10.96 \%$ for neurological symptoms to $21.82 \%$ for dermatological symptoms. Borderline normal values ranged from $17.56 \%$ for nephrological symptoms to $40 \%$ for gynecological symptoms.

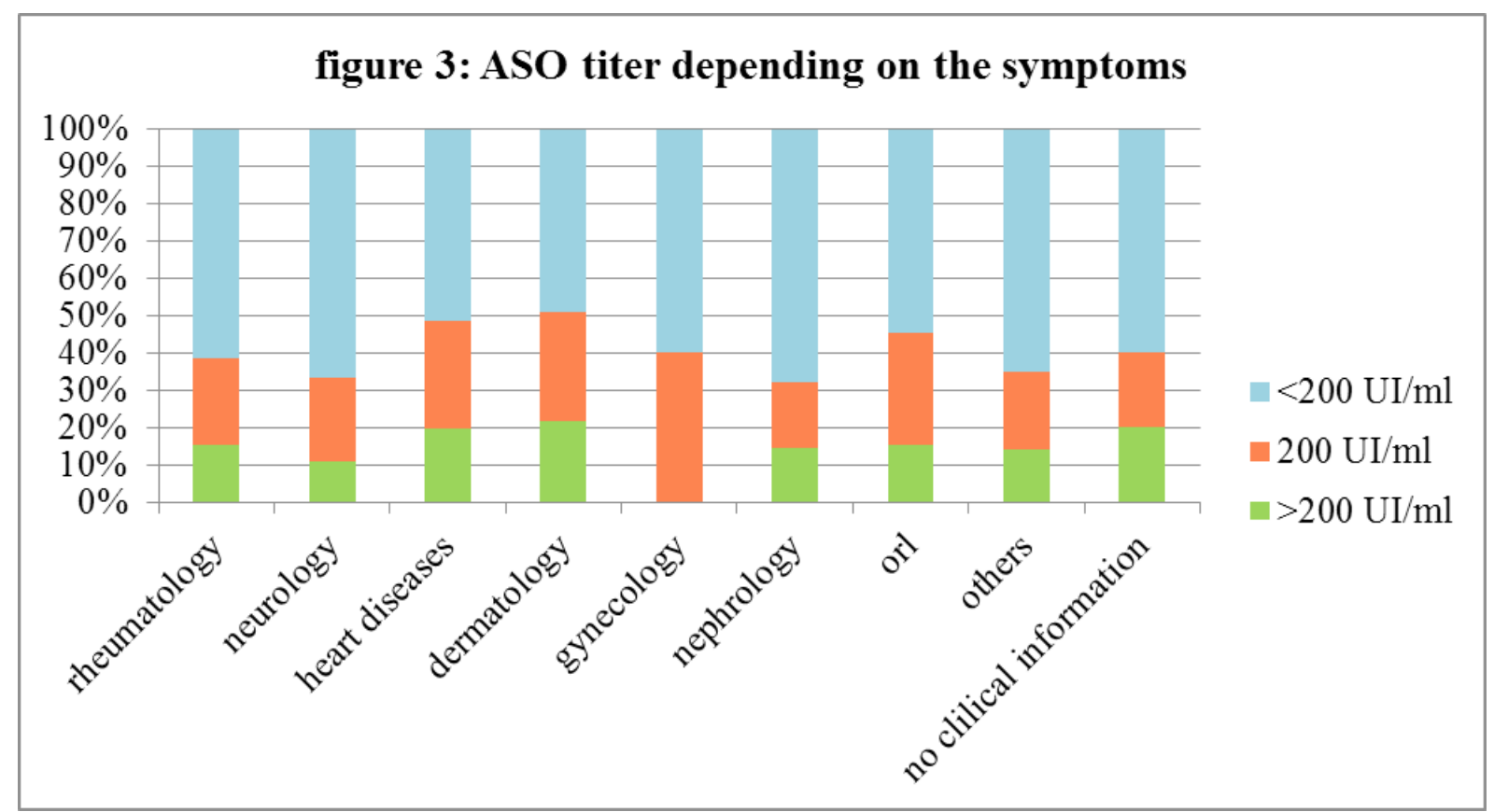

Figure 3: ASO titre and symptoms

\section{Discussion}

The prevalence of streptococcal infections remains very high in Madagascar and the severity of its complications reinforces the need of a precise diagnosis, mainly an immunological proof of the infection. The two most prescribed analyses are ASO and antistreptodornase ${ }^{11}$, especially when auto immune complications occurred, such as rheumatic fever or a post streptococcal glomerulonephritis. Some guidelines are now available especially for rheumatologic symptoms ${ }^{3,5,12}$. The main finding in our study is that most of ASO requests showed a low level of ASO titre, despite the level of endemicity of streptococcal infection in Antananarivo. Moreover, even if the level of ASO titer is high, it doesn't mean 
necessarily that the patient has a true post streptococcal infection because the antibodies titre decrease slowly and may persist longtime after the infection ${ }^{13}$. Besides, a single ASO titre assay has some limitations, especially with regard to chronic nasopharyngeal group A beta hemolytic streptococcus carriage status. The majority of the patients having joint complaints who went to our labs were aged of 20 to 30 years, which is not compatible with the typical presentation of acute rheumatic fever usually occurring in children aged of 5 yrs. to 14 yrs. ${ }^{14}$. The first hypothesis which can explain this fact is that our physicians did not have appropriate and updated knowledge about ASO request that's why they prescribed it as a routine analysis. The second hypothesis is that they are thinking about the post streptococcal arthritis instead of others causes of arthralgia in adults ${ }^{15}$. The evaluation of ASO titer is a part of the current guidelines for the diagnosis of acute rheumatic fever ${ }^{16}$. There is an increase of the ASO titer one week after the infection with a maximal level in 3 weeks, and the level of antistreptodornase reaches its maximal level in 6 weeks ${ }^{17}$. It's suggested that both of them must be evaluated ${ }^{18}$. The physician also needs to put a strong emphasis on the seroconversion which is more important than a high level of antibodies found alone ${ }^{13}$.

Chorea is one of the symptoms which may justify a request of ASO titer ${ }^{19}$ and it occurs mainly among young women during teenage ${ }^{20}$.

For heart diseases, it is known that they are part of the most severe complications of post streptococcal diseases in developing countries, and they are part of prognostic criteria for the issue of the disease ${ }^{21}$.

The ASO titer is useful to diagnose a post streptococcal glomerulonephritis, in addition to a renal biopsy, but they are rare among adults ${ }^{22}$. Moreover, ASO titer may be under than $200 \mathrm{U} / \mathrm{ml}$ in adults aged more than 60 $\mathrm{yrs}^{23}$. So, only $2.4 \%$ of our requests are justified in case of renal symptoms.

About dermatological symptoms, they may be due to the streptococcus, such as impetigo of cellulitis, or due to post streptococcal diseases, such as emarginated erythema or Meynet's nodule ${ }^{20}$. So, only $0.5 \%$ of our demands were relevant.

Recurrent tonsillitis may be due to bacteria or viruses, and some authors recommend an evaluation of ASO titer to distinguish both of them ${ }^{24}$; it is also the case for pharyngitis in infants ${ }^{25}$. But it is better to perform a bacteriological diagnosis to find the presence or not of streptococci because the other sites of streptococci may increase the ASO titer level leading to a misdiagnosis of an infection.

For $19.72 \%$ of our demands, the requests were not relevant (for example, a request for ASO titration is not relevant in stiff neck or in chickenpox), and it is essential to encourage physicians to update their knowledge by searching data through the Internet for example.

There are some limitations in our study. Until now, there was no study which aimed to determine the cut off for ASO level among the population living in Antananarivo, so we retained as significant level a titer of ASO more than $200 \mathrm{U} / \mathrm{ml}$. Indeed, the ASO level may vary depending age groups of patients, site of streptococcal infection and different seasons, and on each country ${ }^{15,26,27}$ and we think that it may be one of the research topics here in Antananarivo.

Finally, group A streptococci are part of normal flora in the nasopharynx and the test must be repeated in case of high level in order to show the increase of the titre in a case of a true infection. Nonetheless, it is not often feasible to obtain acute and convalescent sera, hence the use of a single cut off level.

\section{Conclusion}

We found that the majority of ASO requests don't show a significant level in Antananarivo. We think that maybe the baseline level of ASO is lower than $200 \mathrm{U} / 1$ so the next step is to perform a study among general population in order to determine the normal value of this parameter.

\section{Conflict of interest}

None

\section{References}

1. McDonald M, Currie BJ, Carapetis JR. Acute rheumatic fever: a chink in the chain that links the heart to the throat? The Lancet infectious diseases. 2004 Apr;4(4):240-5.

2. Steer AC, Law I, Matatolu L, Beall BW, Carapetis JR. Global emm type distribution of group A streptococci: systematic review and implications for vaccine development. The Lancet infectious diseases. 2009 Oct;9(10):611-6.

3. Foster.H, Khulood Khawaja .B. When to request a paediatric rheumatology opinion. Current Paediatrics.2005:15, 1-8

4. National Heart Foundation of Australia and the Cardiac Society of Australia and New Zealand. Diagnosis and management of acute rheumatic fever and rheumatic heart disease in Australia. An evidence- 
based review. June 2006 National Heart Foundation of Australia.

5. van Toorn R, Weyers HH, Schoeman JF. Distinguishing PANDAS from Sydenham's chorea: case report and review of the literature. Eur J Paediatr Neurol. 2004;8(4):211-6.

6. Jansen TL, Janssen M, de Jong AJ, Jeurissen ME. Post-streptococcal reactive arthritis: a clinical and serological description, revealing its distinction from acute rheumatic fever. Journal of internal medicine. 1999 Mar;245(3):261-7.

7. Horino T, Takao T, Terada Y. A case of poststreptococcal reactive arthritis in which lesions were detected with $[18 \mathrm{~F}]$-fluorodeoxyglucose positron emission tomography-CT imaging and magnetic resonance imaging. Modern rheumatology / the Japan Rheumatism Association. Jun;20(3):287-90.

8. Jackson SJ, Steer AC, Campbell H. Systematic Review: Estimation of global burden of non-suppurative sequelae of upper respiratory tract infection: rheumatic fever and post-streptococcal glomerulonephritis. Trop Med Int Health. Jan;16(1):2-11.

9. Seckeler MD, Hoke TR. The worldwide epidemiology of acute rheumatic fever and rheumatic heart disease. Clinical epidemiology.3:67-84.

10. Kaplan EL, Rothermel CD, Johnson DR. Antistreptolysin $\mathrm{O}$ and anti-deoxyribonuclease $\mathrm{B}$ titers: normal values for children ages 2 to 12 in the United States. Pediatrics. 1998 Jan;101(1 Pt 1):86-8.

11. Martins TB, Hoffman JL, Augustine NH, Phansalkar AR, Fischetti VA, Zabriskie JB, et al. Comprehensive analysis of antibody responses to streptococcal and tissue antigens in patients with acute rheumatic fever. International immunology. 2008 Mar;20(3):445-52.

12. Eichbaum QG, Hughes EJ, Epstein JE, Beatty DW. Rheumatic fever: autoantibodies against a variety of cardiac, nuclear, and streptococcal antigens. Annals of the rheumatic diseases. 1995 Sep;54(9):740-3.

13. Johnson DR, Kurlan R, Leckman J, Kaplan EL. The human immune response to streptococcal extracellular antigens: clinical, diagnostic, and potential pathogenetic implications. Clin Infect Dis. Feb 15;50(4):481-90.

14. Steer AC, Danchin MH, Carapetis JR. Group A streptococcal infections in children. Journal of paediatrics and child health. 2007 Apr;43(4):203-13.

15. Deligny C, Arfi S. Characteristics of post- streptococcal reactive arthritis in non-Caucasian. Revue du rhumatisme.2003; 70:107-110

16. Moorthy LN, Gaur S, Peterson MG, Landa YF, Tandon M, Lehman TJ. Poststreptococcal reactive arthritis in children: a retrospective study. Clinical pediatrics. 2009 Mar;48(2):174-82.

17. Steer AC, Vidmar S, Ritika R, Kado J, Batzloff M, Jenney AW, et al. Normal ranges of streptococcal antibody titers are similar whether streptococci are endemic to the setting or not. Clin Vaccine Immunol. 2009 Feb;16(2):172-5.

18. Carapetis JR, McDonald M, Wilson NJ. Acute rheumatic fever. Lancet. 2005 Jul 9-15;366(9480):15568.

19. Walker KG, Lawrenson J, Wilmshurst JM. Neuropsychiatric movement disorders following streptococcal infection. Developmental medicine and child neurology. 2005 Nov; 47(11):771-5.

20. Martin JM, Green M. Group A streptococcus. Seminars in pediatric infectious diseases. 2006 Jul;17(3):140-8.

21. Carapetis JR. Rheumatic heart disease in developing countries. The New England journal of medicine. 2007 Aug 2;357(5):439-41.

22. Niewold TB, Ghosh AK. Post-streptococcal reactive arthritis and glomerulonephritis in an adult. Clinical rheumatology. 2003 Oct;22(4-5):350-2.

23. Matsubara M, Furuta T, Saito T, Yoshinaga K, Taguma T. [Three elderly cases of endocapillary glomerulonephritis and nephrotic syndrome]. Nihon Jinzo Gakkai shi. 1989 Mar;31(3):253-8.

24. Borschmann ME, Berkowitz RG. One-off streptococcal serologic testing in young children with recurrent tonsillitis. The Annals of otology, rhinology, and laryngology. 2006 May;115(5):357-60.

25. Shulman ST, Ayoub EM. Poststreptococcal reactive arthritis. Current opinion in rheumatology. 2002 Sep;14(5):562-5.

26. Sethi S, Kaushik K, Mohandas K, Sengupta C, Singh S, Sharma M. Anti-streptolysin O titers in normal healthy children of 5-15 years. Indian pediatrics. 2003 Nov;40(11):1068-71.

27. Nava A, del Rio LE, Aguilar CM, Mazariegos GR, Navarro SN, Navarro CR, et al. [Serum levels of antistreptolysin $\mathrm{O}$ in teenagers from Mexican urban and rural areas]. Rev Alerg Mex. 2008 Sep-Oct;55(5):196200. 